\title{
Emergency disposal and management of medical waste during the COVID-19 outbreak in China
}

\author{
Liyuan Liu ${ }^{1,+}$, Guanglong $\mathrm{Wu}^{2,+}$, Qinzhong Feng ${ }^{1}$ and Yang Chen ${ }^{1, *}$ \\ ${ }^{1}$ College of Resources and Environment, University of Chinese Academy of Sciences, 100049 Beijing, China \\ ${ }^{2}$ Foreign Environmental Cooperation Center, Ministry of Ecology and Environment of People's Republic of China, Beijing 100035, China \\ $\dagger$ These authors contributed equally
}

\begin{abstract}
At the beginning of 2020, COVID-19 began to explode on a large scale around the world, with medical and health institutions around the world are facing great pressure. During this period, medical institutions that treat patients with COVID-19 will also generate a large amount of medical waste. If not handled properly, infectious viruses will enter the environment and cause secondary pollution and new epidemic. Wuhan was the first city to have a large-scale outbreak during the outbreak. In the early stage of the outbreak, the relevant competent departments of medical and health institutions and medical waste disposal agencies in China quickly and timely issued a series of technical guidelines and Management measures to control secondary pollution of medical waste during COVID-19. This article analysed the medical waste disposal capacity in Wuhan city, Hubei Province and China at 2020, which also introduce the medical waste treatment measures taken in China during the outbreak, hoping to provide technical reference for other countries.
\end{abstract}

\section{Introduction}

At the beginning of 2020, COVID-19 began to explode on a large scale around the world, with medical and health institutions around the world are facing great pressure. During this period, medical institutions that treat patients with COVID-19 will also generate a large amount of medical waste ${ }^{[1]}$. If not handled properly, infectious viruses will enter the environment and cause secondary pollution and new epidemic ${ }^{[2-3]}$. China was the first country to have a large-scale outbreak during the outbreak [4-5].

Major outbreaks such as H1N1 influenza A, Ebola virus, Middle East Respiratory Syndrome Coronavirus, and other major outbreaks have broken out in the international community on a large scale in last tens of years. Similarly, the outbreak of COVID-19 has made the beginning of 2020 unusual to the world, which posing a huge threat to public life and health, and a serious challenge to global public health security. China was suffered from the pandemic at 2020. Although China has established a basic framework for emergency medical waste disposal after SARS, it has also faced many problems when responding to the new situation of medical waste disposal during the COVID-19 epidemic: for example, the emergency response mechanism is not complete and efficiency, the medical waste disposal system lacks effective supervision, the inter-departmental management coordination is insufficient, the collection and transportation system is imperfect, and even when the amount of medical waste surges, the disposal capacity cannot be quickly and effectively supplemented. Although isolation, diagnosis, treatment, protective measures and rehabilitation have all started from scratch, China has effectively prevented the deep spread of COVID-19 by relying on scientific and precise preventive measures taken by the government and the joint defence and control mechanism established by China. However, through the urgent introduction of a series of emergency disposal technical documents and the joint management of relevant management agencies, a full-process closed-loop medical waste management system involving the epidemic situation was formed, which finally steadily responded to various problems that occurred during the new epidemic. With the strong support of the leaders and the government, China has fought hard and successfully to fight this epidemic.

This article will analysis the Medical waste disposal capacity in China, introduce the Medical waste treatment measures taken in China during the outbreak, hoping to provide technical reference for other countries.

\section{Materials and methods}

Data collection was carried out during site visits from January to June 2020. According to the official statistical data of National Health Commission of the People's Republic of China (NHC) and the Ministry of Ecology and Environment of the People's Republic of China (MEE), the changes in the amount, disposal capacity and compliance rate of medical waste in China since the outbreak were analysed. Technical and management

* Corresponding author: chenyang@ucas.ac.cn 
requirements, analysed the precautions and measures that can be taken during the treatment of medical waste during emergency disposal situations.

\section{Results and discussion}

\subsection{Medical waste generation and disposal situation in China during the COVID-19 outbreak}

Since January 2020, NHC began to announce the status of confirmed COVID-19 patient cases daily ${ }^{[6]}$, and China's medical waste disposal information is mainly published on the public website by MEE ${ }^{[7]}$, including daily national medical waste collection volume, disposal volume, conventional and emergency disposal facility disposal capacity and other information.

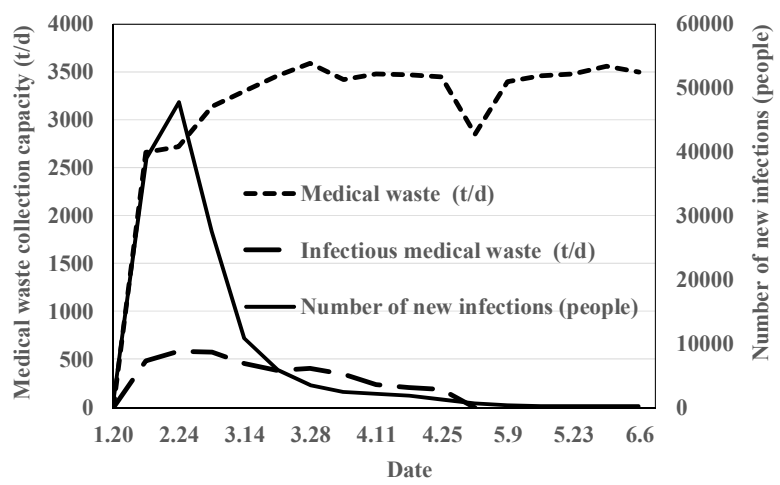

Fig. 1. The number of new COVID-19 infected patients and daily medical waste generation in China from 2020.1 to 2020.6

Fig. 1 shows the number trend of people infected with COVID-19 in China from January to early June 2020. With the gradual increase of COVID-19 patients (it peaked on February $24^{\text {th }}$ ), the amount of medical waste collected gradually increased, and the infectious waste proportion in medical waste also gradually increased, reaching $21.61 \%$ on February $24^{\text {th }}$.

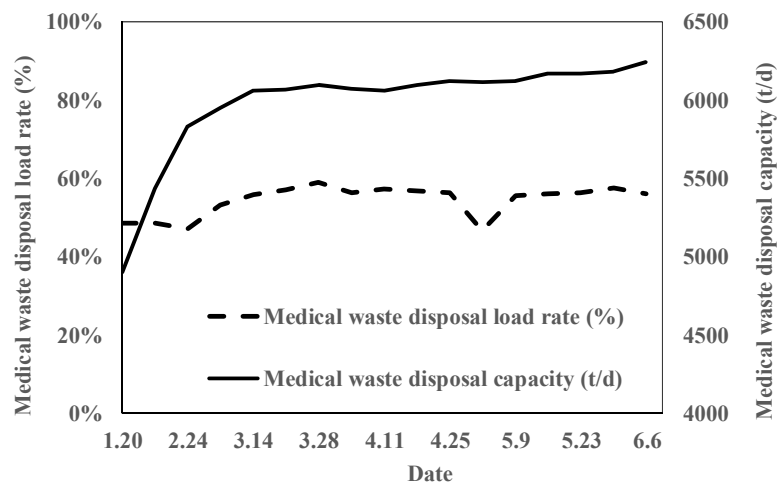

Fig. 2. Medical waste disposal capacity in China from 2020.1 to 2020.6

It can be seen from Fig. 2, China's medical waste disposal capacity increased from 4,902.8 $\mathrm{t} / \mathrm{d}$ to $6,245.4 \mathrm{t} / \mathrm{d}$ from January $20^{\text {th }}$ to June $6^{\text {th }}$. With the rapid improvement of the national medical waste disposal capacity in the short term, the average load rate increased from $48.6 \%$ (Feb. $\left.11^{\text {th }}\right)$ to $60.8 \%$ (Apr. $\left.10^{\text {th }}\right)$. As the number of patients diagnosed with COVID-19 slows down, the proportion of medical waste in the national epidemic gradually decreases, from $21.61 \%$ (Feb. $24^{\text {th }}$ ) in peak period to $5.41 \%$ (April $25^{\text {th }}$ ), and the operating load rate also tends to stabilize at around 56\%. And from April 2020, the temporary disposal rate of all temporary medical waste in China was $100 \%$. In this reporting period, China accumulated to disposal 447,000 tons medical waste.

In addition to various measures to quickly improve the disposal capacity of medical waste in 3 months, the Chinese government has also carried out classification and diversion management of all medical waste ${ }^{[8]}$ :

(1) During the epidemic period, mobile medical waste disposal facilities, hazardous waste incineration facilities, domestic garbage incineration facilities, industrial furnaces and other facilities can be used for emergency treatment of new coronary pneumonia epidemic medical waste;

(2) Centralized medical waste disposal facilities shall be used primarily for medical waste related to the pandemic or other medical waste that are not fitted for emergency disposal facilities. Other medical waste may be decentralized so as to be disposed in household waste incineration facilities and other emergency disposal facilities.

(3) When the disposal capacity of a centralized medical waste disposal facility does not meet actual needs, and it needs to transport medical waste related to the pandemic to movable medical waste disposal facilities, hazardous waste incineration facilities, household waste incineration facilities, industrial furnaces and other emergency disposal. Disinfection shall be strengthened to reduce the risk of infection.

(4) According to the cross-regional coordination mechanism for emergency disposal, the waste can be transferred to the centralized treatment facilities for medical waste in nearby areas for disposal.

(5) Under the unified leadership of the people's government at the local level, the local eco-environmental authorities at all levels, in collaboration with health and other departments, will improve the emergency response coordination mechanism and jointly organize the emergency treatment of medical waste for the new coronary pneumonia epidemic. Taking district-based cities as the unit, coordinate emergency disposal facility resources, establish a list of emergency treatment resources for medical waste of new coronary pneumonia epidemics, and release emergency disposal information in a timely manner.

\subsection{Medical waste generation and disposal situation in Hubei Province and Wuhan City during the COVID-19 outbreak}

Hubei Province and Wuhan City were the region had the most diagnosed COVID-19 patients in China in 2020. 


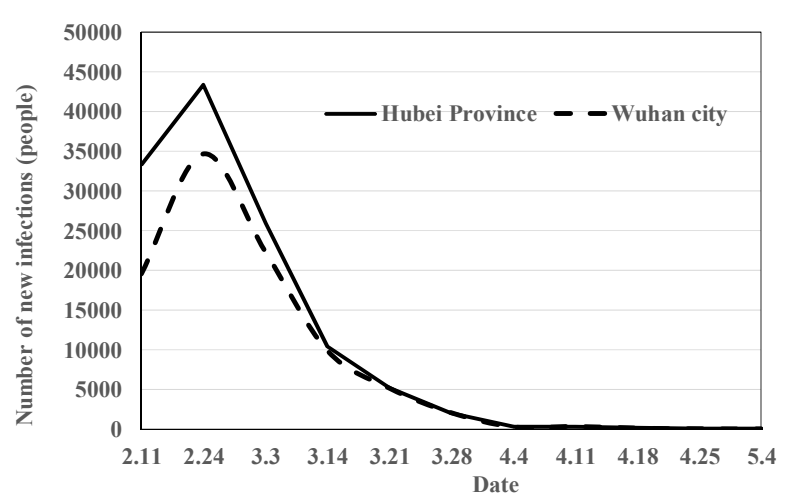

Fig. 3. The number of new COVID-19 infected patients in Hubei Province and Wuhan City from 2020.1 to 2020.5

As can be seen from Fig. 3, the number of new infections in Hubei Province and Wuhan City also peaked on February 24, and the number dropped to 0 in May, which is similar to the situation of COVID-19 infection in China.

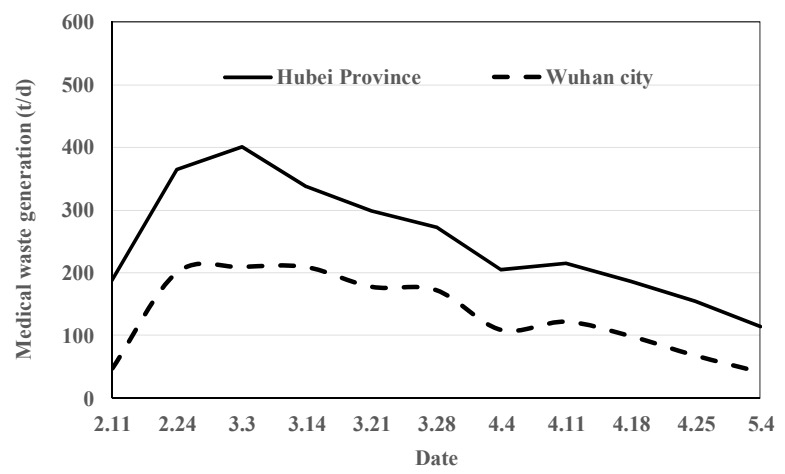

Fig. 4. Medical waste generation situation in Hubei Province and Wuhan City from 2020.1 to 2020.5

The amount of medical waste generated has gradually decreased with the decrease in the number of new infections (Fig. 4). Since May 2020, the amount of medical waste generated in Wuhan has stabilized at 41-43 $\mathrm{t} / \mathrm{d}$, basically at the level of medical waste generated before the epidemic.

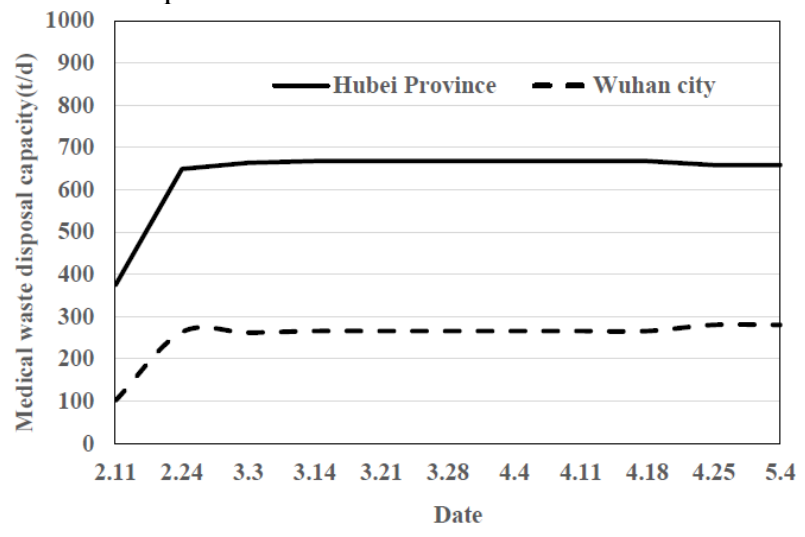

Fig. 5. Medical waste disposal capacity in Hubei Province and Wuhan City from 2020.1 to 2020.5

As can be seen from Fig. 5, Hubei Province, as the hardest hit by COVID-19, rapidly expanded its medical waste disposal capacity in two months, from $180 \mathrm{t} / \mathrm{d}$ to $667.4 \mathrm{t} / \mathrm{d}$ to meet the medical waste disposal needs during the epidemic.

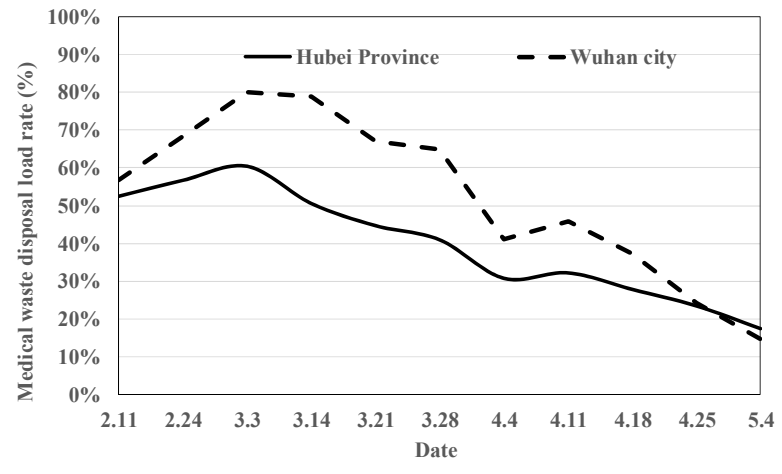

Fig. 6. Medical waste disposal load rate in Hubei Province and Wuhan City from 2020.1 to 2020.5

As the first outbreak of the outbreak, Wuhan City is facing more severe medical waste disposal pressure than other cities. The operating load rate of medical waste disposal facilities increased from $57 \%\left(\mathrm{Feb} .11^{\text {th }}\right)$ to $93.2 \%$ $\left(\right.$ Mar. $\left.9^{\text {th }}\right)$, and on March $2^{\text {nd }}, 100 \%$ disposal of medical waste was achieved on that day, and the safe disposal of accumulated medical waste was completed. As of May 2020 , with the gradual decrease in the number of confirmed diagnoses in Hubei Province and Wuhan City, the collection and disposal volume of medical waste involved in the epidemic situation has stabilized, and the operational load rate of medical waste disposal facilities in Hubei Province and Wuhan City has stabilized.

\subsection{China's medical waste management during the COVID-19 outbreak}

Inappropriate application and management of medical waste treatment technologies will create potential risks to human health and environment. In the early stage of the outbreak, the relevant competent departments of medical and health institutions and medical waste disposal agencies quickly and timely issued a series of technical guidelines and Management measures to control secondary pollution of medical waste during COVID-19 epidemic period ${ }^{[9-18]}$. The management of medical waste emergency treatment exposed by the COVID-19 epidemic has attracted great attention from relevant Chinese departments. Ten departments including NHC and MEE jointly issued the "Work Plan for Comprehensive Treatment of Medical Waste" in Feb.26th $2020^{[19]}$. The work plan requires that, at least one centralized medical waste disposal facility that meets the operational requirements must be built in each city by the end of 2020, and each city has to establish a whole medical waste collection, transport and disposal system. In addition, the plan also covers the classification and management of internal waste in medical institutions, the disposal of medical waste, the management of domestic garbage, the recycling of infusion bottles (bags), the implementation of special waste management and protection of medical institutions, the implementation of various measures, doing a good job of publicity and guidance, and carrying out summary evaluations, and clarified the responsible department of each work. These measures will also play a good foundation for the subsequent management of 
medical waste in China in response to large-scale outbreaks and emergencies.

In China, medical wastes are divided into five categories for management according to their characteristics ${ }^{[20]}$. Five categories of medical waste include infectious wastes, pathological wastes, injury wastes, pharmaceutical wastes and chemical wastes ${ }^{[21-23]}$. The major difference between medical waste generated during the coronavirus (COVID-19) pandemic and conventional medical waste lies in the significant increase in infectious waste. For example, the medical waste generated during the COVID-19 pandemic includes: (1) Medical waste generated in designated medical institutions, fever clinics and quarantine points, and sludge from wastewater treatment. (2) Excreta of patients after disinfection in medical institutions without wastewater treatment system; household waste produced by patients in quarantine or with suspected epidemic admitted by medical institutions. (3) Articles contaminated with blood, body fluids or excreta of diagnosed and suspected patients, such as used cotton swabs, gauze and other dressings, disposable sanitary products, disposable medical devices, etc. (4) Specimens, strains, culture media, etc. generated in teaching, research and other medical activities related to COVID-19. According to virus experts, medical waste generated during the COVID-19 pandemic is highly infectious and has a greater risk of infection than usual medical waste. (5) In addition, garbage and waste produced in fever clinics and ward units (rooms) where patients with diagnosed and suspected COVID-19 are diagnosed and treated shall be collected separately by corresponding medical institutions as medical waste. Where a hospital has a quarantine zone, garbage and waste generated in the quarantine zone shall also be managed as medical waste.

Based on fundamental facility conditions of medical waste disposal which could be used in region, classified collection of medical waste source and orderly convergence of applicability of subsequent disposal facilities shall be carried-out in an integrated way. Safe disposal of COVID-19 medical waste shall follow the principle of life-cycle process management, manage and control the whole process of medical waste collection, categorization, storage, transportation, treatment and disposal.

\subsection{China's technical route of medical waste disposal during the COVID-19 outbreak}

In addition, technical route of medical waste in China during the COVID-19 epidemic period including three factors as below:

(1) Scientifically choose medical waste disposal technology.

It should be disposed by high-temperature incineration, and can also be disposed by non-incineration methods such as high-temperature steam sterilization, microwave sterilization, chemical sterilization, etc., and ensure the treatment effect ${ }^{\text {[24-28]. }}$.

(2) Reasonably determine emergency disposal facilities.
Give priority to the use of centralized medical waste disposal facilities in the administrative area: when the existing disposal capacity in the area cannot meet the emergency disposal needs of medical waste in an epidemic situation, the emergency plan should be immediately initiated, and the mobile medical waste disposal facilities included in the emergency disposal resource list , Hazardous waste incineration facilities, domestic waste incineration facilities, industrial furnaces and other facilities to carry out emergency disposal, implement fixed-point management, and do a good job in sanitation and epidemic prevention; they can also be transferred to nearby areas for medical waste concentration according to the cross-regional coordination mechanism for emergency disposal facilities. For special reasons, if the conditions for centralized disposal are not met, medical waste can be incinerated and disposed of in accordance with the plan determined by the local people's government, and equipped with corresponding pollutant treatment measures to avoid secondary environmental pollution.

(3) Facilitate local emergency treatment of medical institutions.

Medical institutions adopt portable medical waste disposal facilities for emergency treatment of medical waste on their own or in near medical institutions, which can be exempted from procedures such as environmental impact assessment and medical waste management permits, but the disposal site should be reasonably set to avoid drinking water source protection areas and centralized residence Districts and other environmentally sensitive areas, and report to the municipal health and ecological and environmental authorities at the district level.

\section{Conclusion}

Whether in routine management or when responding to sudden environmental pollution or public health incidents, this management system has the advantages and important role of orderly, efficient and standardized realization of medical waste reduction and harmless disposal, which can be used for other The medical waste disposal enterprises and relevant management departments still in the epidemic period provide reference.

\section{Acknowledgements}

This work was financially supported by Chinese Academy of Sciences Literature and Information Capacity Building Project.

\section{References}

1. H. Yu, X. Sun, W. D. Solvang, X. Zhao. Reverse Logistics Network Design for Effective Management of Medical Waste in Epidemic Outbreaks: Insights from the Coronavirus Disease 2019 (COVID-19) Outbreak in Wuhan (China). Int. J. Environ. Res. Public Health 17, 1770. (2020)

2. S. Saadat, D. Rawtani, C. M. Hussain. Environmental 
perspective of COVID-19. Science of the Total Environment 728, 138870. (2020)

3. Y. Zhu, J. Xie, F. Huang, L. Cao. Association between short-term exposure to air pollution and COVID-19 infection_Evidence from China. Science of the Total Environment 727, 138704. (2020)

4. J.T. Wu, K. Leung, G.M. Leung. Nowcasting and forecasting the potential domestic and international spread of the 2019-ncov outbreak originating in wuhan, china: A modelling study. Lancet. (2020)

5. C. Huang, Y. Wang, X. Li, L. Ren, J. Zhao, Y. Hu, L. Zhang, G. Fan, J. Xu, X. Gu. Clinical features of patients infected with 2019 novel coronavirus in wuhan, china. Lancet. (2020)

6. PR China National Health Commission. 2020. Daily update of the Chinese COVID-19 epidemic situation (in Chinese).

http://www.nhc.gov.cn/xcs/xxgzbd/gzbd_index.shtml

7. PR China Ministry of Ecology and Environment. 2020.1. Notice on environmental management of COVID-19 medical waste (in Chinese).

http://www.gov.cn/xinwen/2020-

01/23/content 5471863.htm

8. PR China Ministry of Ecology and Environment. Management and technical guidelines for emergency disposal of medical waste during the COVID-19 epidemic (On Trial). (In Chinese). (2020-1-29)

http://www.gov.cn/xinwen/2020-

01/29/content_5472997.htm

9. PR China National Health Commission. Notice on the management of medical waste in medical institutions during the COVID-19 epidemic. (In Chinese) (20201-28)

http://www.gov.cn/zhengce/zhengceku/202001/28/content_5472796.htm

10. PR China National Health Commission. Guidelines for the Use of Common Medical Protective Equipment in COVID-19 Prevention and Control (On Trial) (In Chinese) (2020-1-27)

http://www.nhc.gov.cn/xcs/zhengcwj/202001/e71c5d e925a64eafbe1ce790debab5c6.shtml

11. PR China National Health Commission. COVID-19 Case Transfer Work Program (On Trial) (In Chinese) (2020-1-27)

http://www.nhc.gov.cn/yzygj/s7653p/202001/ccee6e c0942a42a18df8e5ce6329b6f5.shtml

12. PR China National Institute of Hospital Administration, National Health Commission. Guidelines for the Supervision of Medical Wastes in Medical Institutions. (In Chinese) (2016-5-30)

http://www.sific.com.cn/static/upload/source/201701 24/9305886a73bb9d296.pdf

13. PR China National Institute of Hospital Administration, National Health Commission. Supervision Process and Indicators of Medical Wastes in Medical Institutions. (In Chinese) (2016-5-30) http://www.sific.com.cn/static/upload/source/201701

\section{4/9305886a73bb9d296.pdf}

14. PR China Ministry of Ecology and Environment. Questions and answers related to medical waste during emergency treatment of domestic waste incineration facilities during the COVID-19 epidemic. (In Chinese) (2020-1-21)

http://huanbao.bjx.com.cn/news/20200210/1041464. shtml

15. PR China Ministry of Ecology and Environment. Standard for pollution control on the municipal solid waste incineration (GB 18485). (In Chinese). (2019) http://kjs.mee.gov.cn/hjbhbz/bzwb/gthw/gtfwwrkzbz /201405/t20140530_276307.htm

16. Department of Ecology and Environment of Jiangsu Province, Jiangsu Commission of Health. Technical guide for collection, storage, transportation and disposal of medical waste related to new coronavirus infection. (In Chinese). (2020-1-29)

https://baijiahao.baidu.com/s?id=165725418505253 $3930 \& w f r=$ spider $\&$ for $=p c$

17. PR China State Council. Law on the Prevention and Control of Infectious Diseases of the People's Republic of China. (In Chinese). (2013-6-29)

http://www.npc.gov.cn/wxzl/gongbao/201310/22/content_1811005.htm

18. PR China State Council. Regulations on the Disclosure of Government Information of the People's Republic of China. (In Chinese). (2019-4-3) http://www.gov.cn/xxgk/pub/govpublic/tiaoli.html

19. PR China National Health Commission. PR China Ministry of Ecology and Environment. PR China National Development and Reform Commission. PR China Ministry of Industry and Information Technology. PR China Ministry of Public Security, PR China Ministry of Finance, PR China Ministry of Housing and Urban-Rural Development, PR China Ministry of Commerce, State Administration for Market Supervision and National Healthcare Security Administration. Work Plan for Comprehensive Treatment of Medical Waste. (In Chinese). (2020-226)

http://www.mee.gov.cn/xxgk2018/xxgk/xxgk10/202 002/t20200227_766362.html

20. Y. Chen, P.J. Li, C. Lupi, Y.Z. Sun, D.D. Xu, Q. Feng, S.S. Fu. Sustainable management measures for healthcare waste in China. Waste Manage 29, 19962004. (2009)

21. PR China Ministry of Health., (2003) Classification catalogue of medical waste (in Chinese). http://www.china.com.cn/chinese/PI-c/458039.htm

22. Y. Chen, Wu Anhua, Feng Qinzong, et al. State Environmental Protection Administration and Medical waste Treatment Technology and Source Classification Countermeasures. Infection Control 6, (In Chinese) (2012)

23. Y. Chen, Q. Ding, X.L. Yang, Z.Y. Peng, D.D. Xu, Q.Z. Feng. Application countermeasures of non- 
incineration technologies for medical waste treatment in China. Waste Management \& Research. 31(12), 1237 -1244. (2013)

24. PR China Ministry of Ecology and Environment. Guidelines on Best Available Technologies of Pollution Prevention for Medical Waste Disposal (On Trial). (In Chinese).

http://www.mee.gov.cn/gkml/hbb/bgg/201201/t2012 0120_222827.htm

25. PR China Ministry of Ecology and Environment. Technical Specifications for Centralized Incineration Facility Construction on Medical Waste (HJ/T 177). (In Chinese).

http://www.mee.gov.cn/ywgz/fgbz/bz/bzwb/other/hj bhgc/200505/t20050524_67082.shtml

26. PR China Ministry of Ecology and Environment. Technical Specifications for Steam-based Centralized Treatment Engineering on Medical Waste (On Trial) (HJ/T 276). (In Chinese).

http://www.mee.gov.cn/ywgz/fgbz/bz/bzwb/other/hj bhgc/200608/W020110127377094539894.pdf

27. PR China Ministry of Ecology and Environment. Technical Specifications for Chemical Disinfection Centralized Treatment Engineering on Medical Waste (On Trial) (HJ/T 228). (In Chinese).

http://www.mee.gov.cn/gkml/zj/gg/200910/t2009102 1_171615.htm

28. PR China Ministry of Ecology and Environment. Technical Specifications for Microwave Disinfection Centralized Treatment Engineering on Medical Waste (On Trial) (HJ/T 229). (In Chinese).

http://www.mee.gov.cn/ywgz/fgbz/bz/bzwb/other/hj bhgc/200603/W020111221394894641492.pdf 